\title{
Investigation of tribo-mechanical properties and structure of specimens obtained by selective laser melting of stainless steel powders
}

\author{
Leonid Belyaev ${ }^{1}$, Aleksey Zhdanov ${ }^{1, a}$ and Valentin Morozov ${ }^{1}$ \\ 1 Department of the mechanical engineering, Vladimir State University, Gorky str. 87, Vladimir, Russia
}

\begin{abstract}
The article presents experimental data about the quality parameters of the stainless steel threedimensional parts obtained by the selective laser sintering procedure. The results of the porosity, tribological properties, tensile test, hardness measurement and density for different values of the focal point position during the engineering process of the three-dimensional parts sintering were given. For parts made from steel powder CL20ES at a laser radiation power of $200 \mathrm{~W}$ in a different focal length range, it is demonstrate that the specimens with the highest density and microhardness values are obtained during the synthesis by using a converging laser beam.
\end{abstract}

\section{Introduction}

Selective laser sintering is one of the most popular process in the production of finished three-dimensional parts in a tight schedule [1-4]. However, in order to ensure the required parameters of strength and durability, the most of finished parts should have a defectless microstructure, the required roughness and have a minimal porosity $[5,6]$. This work presents the experimental studies results of the tribo-mechanical properties of the specimens obtained by selective laser sintering.

\section{Materials and methods}

Specimens synthesis with a $30 \times 30 \times 6 \mathrm{~mm}$ size in a quantity of 10 pieces were performed on the installation Concept Laser M2 (Germany) in a protective atmosphere of nitrogen (Fig. 1). The system is equipped with a $\mathrm{Yb}$ :YAG fiber optic diode-pumped laser, with a capacity of $400 \mathrm{~W}$, manufactured by IPG (Russia). The wavelength of the laser radiation is $1070 \mathrm{~nm}$. The specimens were obtained on the modes: power $200 \mathrm{~W}$, scanning speed $800 \mathrm{~mm} / \mathrm{s}$. The position of the focal laser radiation point was changed from -4 to $+5 \mathrm{~mm}$. As a baseline, the upper level of the spread powder was taken. Besides, the spot diameter in the focus was $50 \mu \mathrm{m}$.

CL20ES powder was used, its chemical composition is close to Chrome Nickel Molybdenum Steel grade "03X17H14M3" (GOST 5632-2014) and steel AISI 316L. This powder is widely used for additive manufacturing, acid and corrosion-resistant specimens, single or small-scale production in engineering industry, automobile industry and others [7].

${ }^{\mathrm{a}}$ Corresponding author: zhdanov@ $\underline{\text { zlsu.ru }}$
The study of the structure was carried out by using the scanning probe microscope NTEGRA Aura and the scanning electron microscope Quanta 3D 200. The x-ray micro-chemical analysis was carried out using the sequential analysis spectrometer ARL ADVANT-X. The density of the specimens was determined by the hydrostatic weighing method in accordance with GOST 25281-82 (ASTM B962-08). Microhardness was measured using the microhardness tester PMT-3 by the indentation of a diamond shaped like a pyramid according to GOST R 8.748-2011 (ISO 14577-1:2002).

For the tensile tests and the evaluation of tribological properties, the specimens obtained at the focal spot position at a distance of $-4 \mathrm{~mm} ; 0 \mathrm{~mm} ;+4 \mathrm{~mm}$ have been selected. The tensile tests were carried out on a tensiletesting machine WDW-100. For this purpose, plane specimens with a total length head of $30 \mathrm{~mm}$ were manufactured (Fig. 2). The study of tribological properties (dry friction coefficients) of the specimens was performed using a CSM tribometer. The study was carried out under normal conditions with a back and forth motion of the counterbody at a load in the range of $10-100 \mathrm{~N}$. The maximal linear velocity is $5 \mathrm{~cm} / \mathrm{s}$, the amplitude of the motion is $22 \mathrm{~mm}$ and a total displacement length of $100 \mathrm{~m}$ using «Pin-On-Disk» methodology.
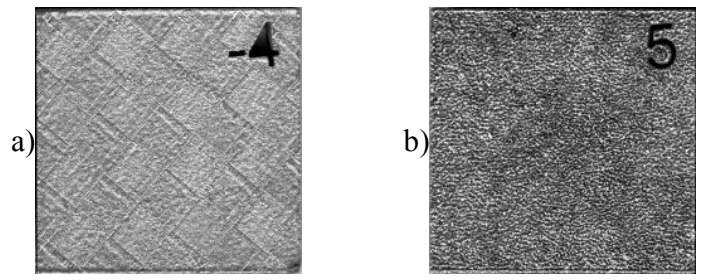

Fig. 1. Picture of the corrosion resistance steel specimens, obtained in different modes:

$a-$ position of the focal point $(-4), b-(+5)$ 


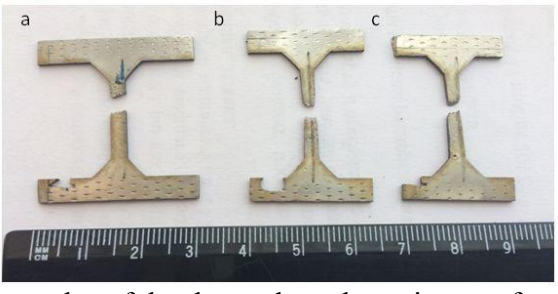

Fig. 2. Examples of dog bone shaped specimens after tensile tests

\section{Results and discussion}

Fig. 3 shows the image of the CL20ES steel powder in initial state obtained with the scanning electron microscope. On the surface of the particles there are satellites, which can reduce the fluidity and stability of bulk density. The investigated steel powders are polycrystals with an average diameter of about $30 \mu \mathrm{m}$ and a microhardness $239 \mathrm{HV}$.
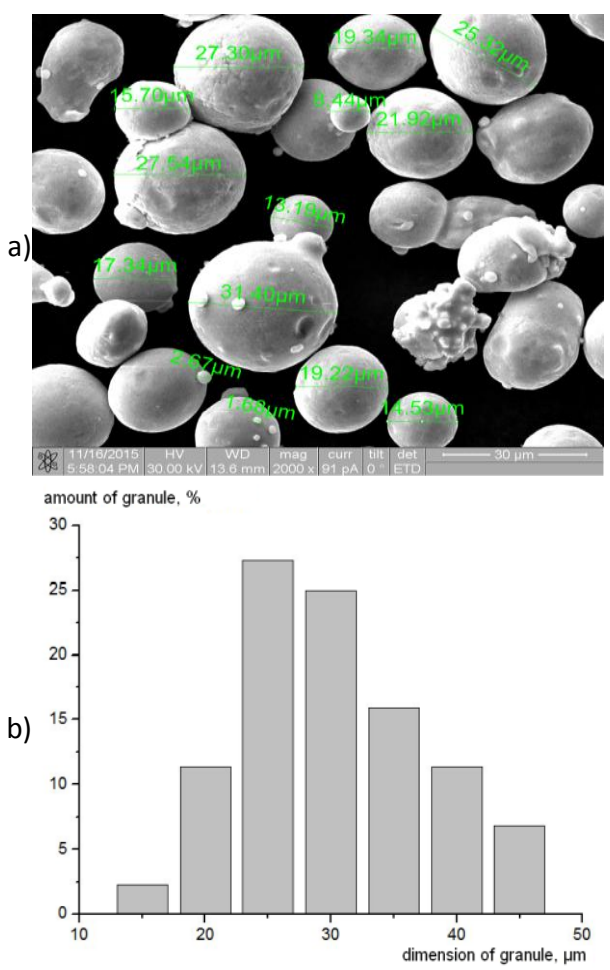

Fig. 3. Steel powder particles of corrosion resistant steel CL20ES (a) and their distribution by size (b)

The results of the comparative $\mathrm{x}$-ray micro-chemical analysis of individual steel powder particles and the chemical composition of the powder according to the manufacturer's data are presented in Table 1. As studies have shown, the content of alloying components in individual steel powder particles differs slightly and corresponds to the composition declared by the manufacturer.
Figure 4 shows the optical images of the specimen at different magnifications, from the CL 20ES powder in its various regions. As the analysis of the microstructure of the specimen shows, the specimen is uniform, with small pores. a)

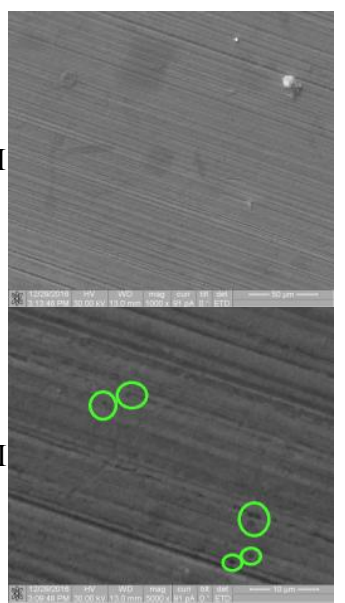

a) I

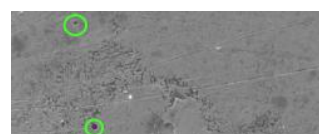

b) II

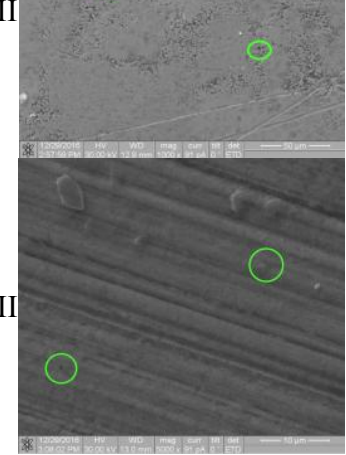

Fig. 4. Optical images of a section of a bulk specimen synthesized from a CL20ES powder:

I - the central region and II - the edge region, with different magnification: a) - $1000 \mathrm{x}$, b) $-5000 \mathrm{x}$

During layered laser synthesis, a porous structure with a low density of $7.15 \mathrm{~g} / \mathrm{cm}^{3}$ was formed (Fig. 4). Pores in the form of irregularly shaped cavities with a length of up to $600 \mu \mathrm{m}$. When measuring the microhardness, the pore size significantly exceeds the diameter of the indentation. Therefore, the microhardness was measured at the metal sites between the pores.

Reducing the position of the focal point leads to a decrease in the diameter of the spot, an increase in the power density of the laser radiation, and the formation of an alloy with a higher density (Fig. 5).

The points are the measured values of the microhardness of the specimens, the line is the

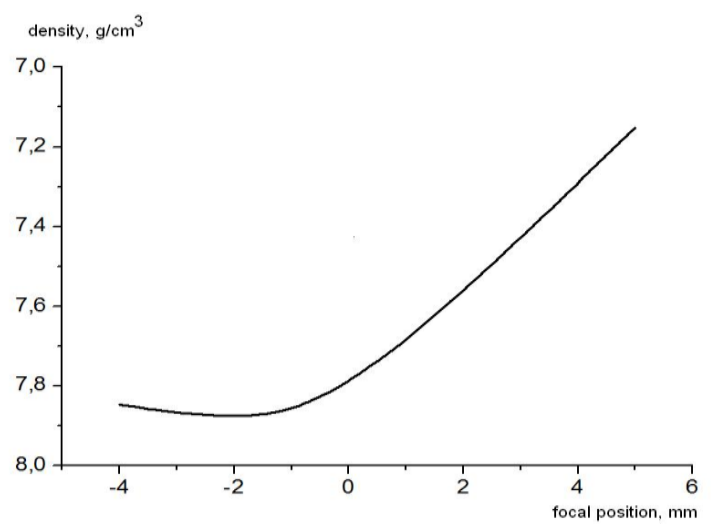

Fig. 5. Dependence of specimen density on the position of the focal point

Table 1. Chemical composition of corrosion resistant steel powder CL20ES

\begin{tabular}{|c|c|c|c|c|c|}
\hline \multirow{2}{*}{} & \multicolumn{5}{|c|}{ Percentage composition of elements by mass } \\
\cline { 2 - 6 } & $\mathrm{Si}$ & $\mathrm{Cr}$ & $\mathrm{Mn}$ & $\mathrm{Ni}$ & $\mathrm{Mo}$ \\
\hline Microchemical analysis & $0.68 \pm 0.12$ & $18.53 \pm 0.19$ & $1.65 \pm 0.12$ & $12.17 \pm 0.30$ & $2.30 \pm 0.88$ \\
\hline Manufacturer's data [8] & $0 \ldots 1.0$ & $16.5 \ldots 18.5$ & $0 \ldots 2.0$ & $10.0 \ldots 13.0$ & $2.0 \ldots 2.5$ \\
\hline
\end{tabular}


approximation of the experimental data on the Boltzmann function using the computer program Origin. An abrupt change in the microhardness is observed when the laser treatment scheme is changed (Fig. 6). When melting steel powder particles with a converging laser beam, a high density and microhardness structure is formed at $400 \ldots 500 \mathrm{MPa}$ higher than when melting the steel powder particles with a divergent beam.

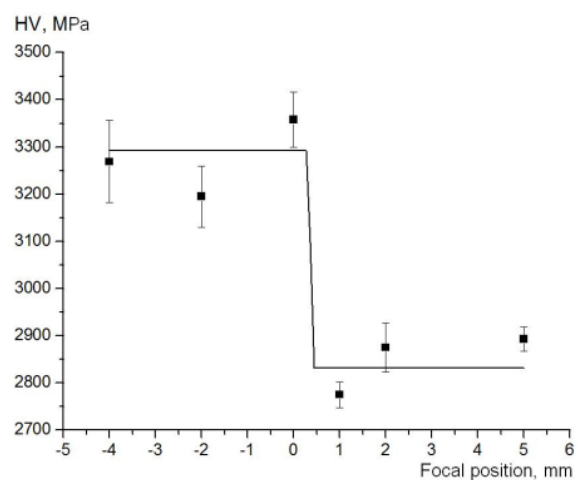

Fig. 6. Dependence of microhardness specimen on the position of the focal point

When focusing laser radiation above the surface to be treated or under it, different mechanisms occur for the formation of a recrystallized layer. In the case of surface treatment with a converging beam of radiation (Fig. 7, a), the power density in the upper parts of the steel powder particles is lower than in the lower ones. As a result, the melt crystallizes sequentially. Conditions are created for the formation of a dense without porous structure with high hardness. An inverse situation is observed in the case of surface treatment by a divergent beam (Fig. 7, b).
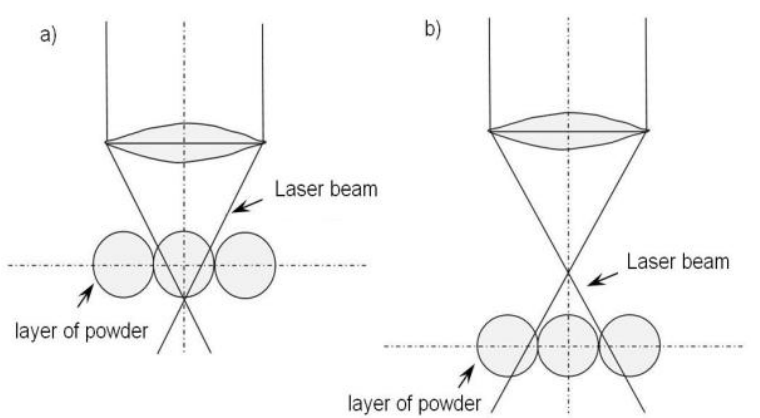

Fig. 7. Processing schemes:

a - melting of steel powder particles with a converging beam, $\mathrm{b}$ - melting of steel powder particles by a divergent beam

Images of the structure of the specimens at different positions of the focal point are used in Figure 8.
The pore sizes are shown in Table 2. The power density on the protruding parts of the steel powder particles is greater than in the depressions. The upper part of the powder layer begins to melt and crystallize earlier than the lower part. As a result, a porous material with a low hardness is formed.

Table 2. Pore sizes in specimens obtained at different positions of the focal point

\begin{tabular}{|c|c|c|}
\hline \multirow{2}{*}{ Focal point position } & \multicolumn{2}{|c|}{ Pore size, $\mu \mathrm{m}$} \\
\cline { 2 - 3 } & $\min$ & $\max$ \\
\hline+2 & 7.23 & 11.97 \\
\hline+3 & 0.72 & 1.6 \\
\hline+5 & 0.73 & 2.72 \\
\hline+6 & 1.46 & 7.36 \\
\hline
\end{tabular}

During the tensile tests, "stress-strain" diagrams have been obtained for the studied specimens (Fig. 9). And also a comparison of the above characteristics with the characteristics of a similar curve for the casted and hot rolled reference steel of Chrome Nickel Molybdenum Steel grade "03X17H14M3".

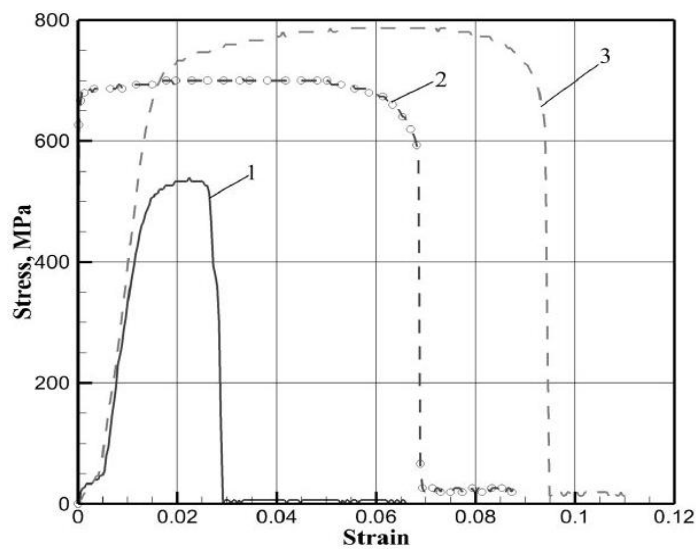

Fig. 9. Stress-strain diagram for dog bone shaped specimens obtained at different positions of the focal point: $1-+4 \mathrm{~mm}$, $2-0 \mathrm{~mm}$ and $3-+4 \mathrm{~mm}$.

The analysis of these diagrams shows that the obtained "stress-strain" curves are qualitatively similar to the same curve for the casted and hot rolled reference steel of Chrome Nickel Molybdenum Steel grade "03X17H14M3". Rupture occurs at the following load values: $534.6 \mathrm{MPa}$; $778.8 \mathrm{MPa}$ and $699.6 \mathrm{MPa}$ for specimens placed at the focal point $+4 \mathrm{~mm} ; 0 \mathrm{~mm}$ and $4 \mathrm{~mm}$ respectively.

Below the graphs of coefficients of friction obtained for back and forth motion of the counterbody and the
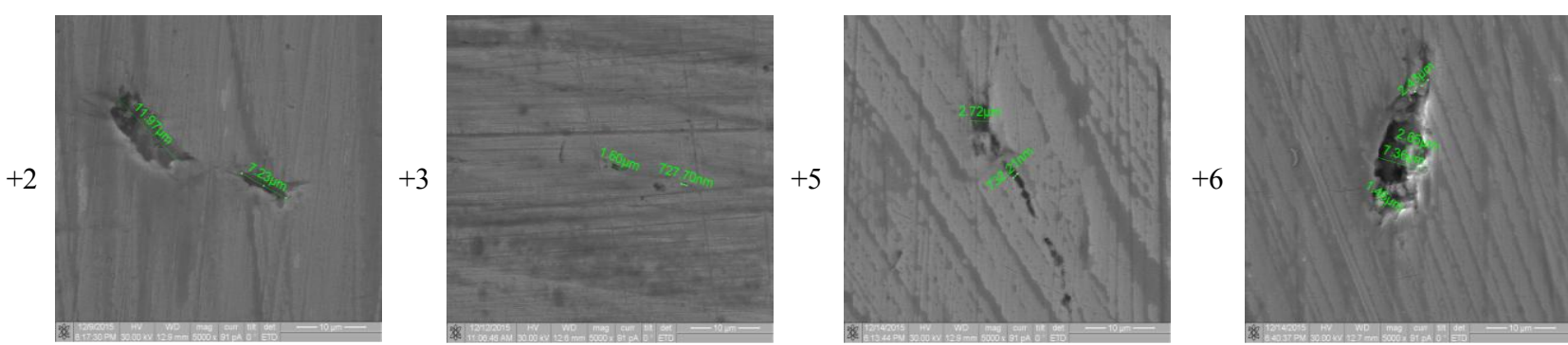

Fig. 8. Optical images of a section of a bulk specimen synthesized from a CL 20ES powder at a different position of the focal point 
a)

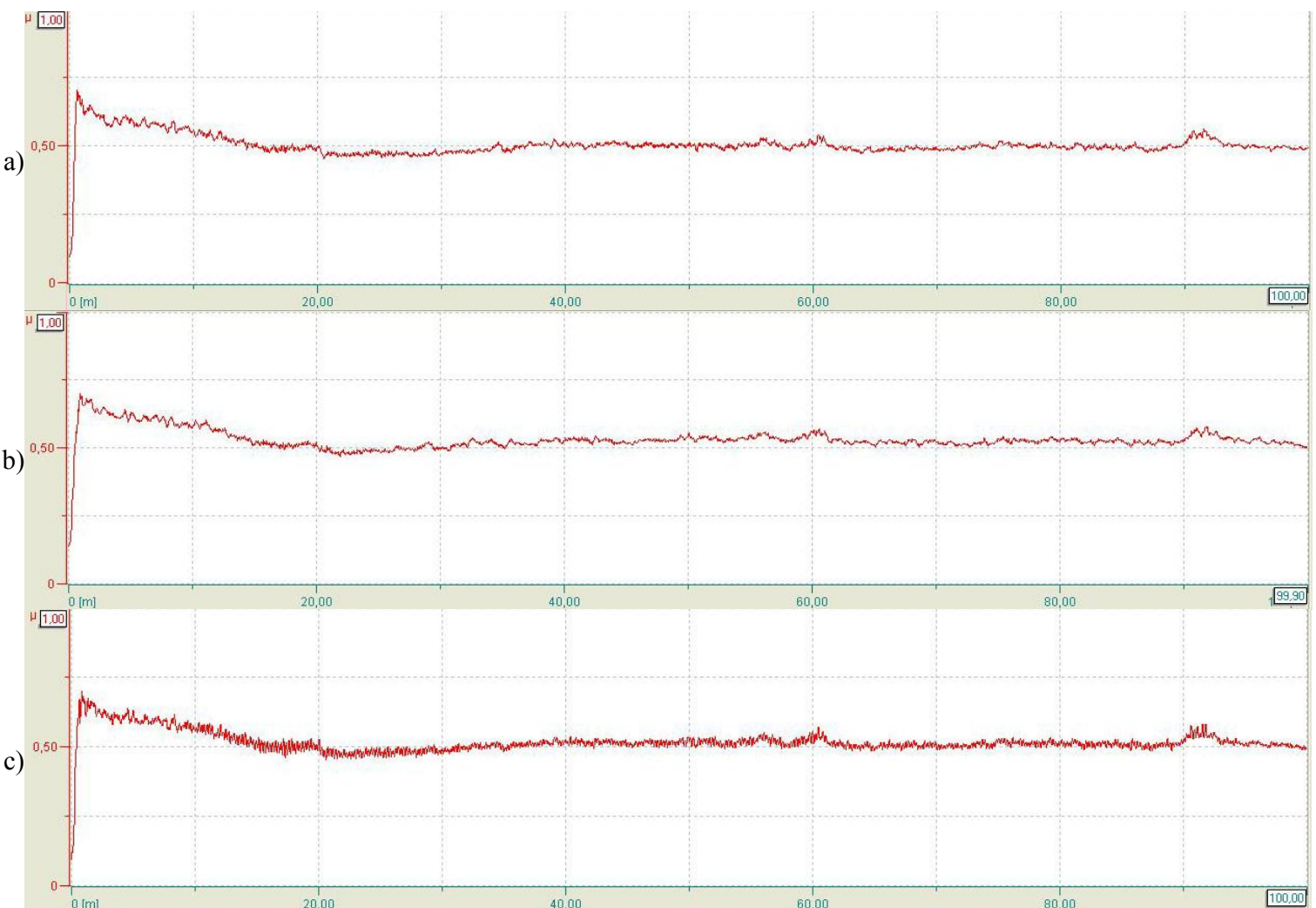

Fig. 10. Friction curves for $-4 \mathrm{~mm}$. specimen: a) forth motion; b) back motion; c) average value for both directions

graph of the average coefficient of friction for a specimen obtained at a focal spot position at a distance of $-4 \mathrm{~mm}$ are presented (Fig. 10). For other specimens, similar graphs were obtained. The values of the coefficients of friction for all the specimens obtained are summarized in a table (Table 3), which also gives comparative values for the Chrome Nickel Molybdenum Steel grade "03X17H14M3", obtained with the same values of the experimental parameters.

The analysis of the presented data shows that the average values of the coefficients of friction for the indicated focal point positions and the "sample-metal" friction pair are $0.519 ; 0.539$ and 0.531 , respectively. The obtained values for the CL20ES steel are similar to the average coefficient of friction of the Chrome Nickel Molybdenum Steel grade "03X17H14M3" which is 0.505 .

\section{Conclusion}

The technological parameters of selective laser melting

Table 3. Friction coefficients of the CL20ES steel specimens obtained at different positions of the focal point compared with

Chrome Nickel Molybdenum Steel grade "03X17H14M3"

\begin{tabular}{|r|c|c|c|c|}
\hline $\begin{array}{r}\text { Focal point } \\
\text { positions, } \\
\mathrm{mm}\end{array}$ & -4 & 0 & +4 & $\begin{array}{c}\text { Chrome Nickel } \\
\text { Molybdenum Steel } \\
\text { grade } \\
\text { "03X17H14M3" } \\
\text { Friction } \\
\text { coefficient, } \mu\end{array}$ \\
\hline forth motion & 0.506 & 0.525 & 0.510 & 0.480 \\
\hline back motion & 0.532 & 0.552 & 0.552 & 0.531 \\
\hline $\begin{array}{c}\text { average value } \\
\text { for both } \\
\text { directions }\end{array}$ & 0.519 & 0.539 & 0.531 & 0.505 \\
\hline
\end{tabular}

are important for obtaining high-quality products with high density, low porosity and hardness. When manufacturing specimens from corrosion resistant steel CL20ES, the best values of density, friction coefficient, tensile test, porosity and microhardness were obtained by recrystallization of the powder layer with a converging beam of laser radiation.

\section{References}

1. E.C. Hussam, C. Bruno, S. Branchu, H. Xiaowei, J.Y. Hasco, R. Guille, OPT LASER ENG 50 (2012), pp. 1779-1784.

2. K. Guan, Z. Wang, M. Gao, X. Li, X. Zeng, Effects of processing parameters on tensile properties of selective laser melted 304 stainless steel, Materials \& Design 50 (2013), 581-586.

3. C. Hauser Selective laser sintering of a stainless steel powder, diss., University of Leeds (2003). 279 p.

4. K. Kempen, L Thijs, B. Vrancken, S. Buls, J. Van Humbeeck, J.P. Kruth, Producing crack-free, high density M2 HSS parts by selective laser melting: pre-heating the baseplate, Proceedings of the 24th international SFF symposium. Laboratory for freeform fabrication (2013) pp. 131-139.

5. E. Bashkirov, K. Khorkov, D. Kochuev, A. Zhdanov, S.Arakelyan, Fundamental Research, 3 (2017).

6. F. Xie, X. He, S. Cao, X. Qu, Structural and mechanical characteristics of porous $316 \mathrm{~L}$ stainless steel fabricated by indirect selective laser sintering. JMPTE 213 (2013). 838-843.

7. T. Dvoryaninova, A. Zhdanov, L. Belyaev, Scientific and technical messenger Volga region 3 (2015).

8. Datasheet CL20ES, ww.conceptlaserinc.com, pdf 